\title{
Chapéu-de-napoleão (thevetia peruviana (pers.) k. schum): novo indicador natural
}

\section{ácido-base}

\author{
Napoleon's hat (thevetia peruviana (pers.) k. schum): new natural indicator acid-base \\ Sombrero de napoleón (thevetia peruviana (pers.) k. schum): nuevo indicador natural ácido-base
}

Recebido: 06/09/2021 | Revisado: 11/09/2021 | Aceito: 13/09/2021 | Publicado: 14/09/2021

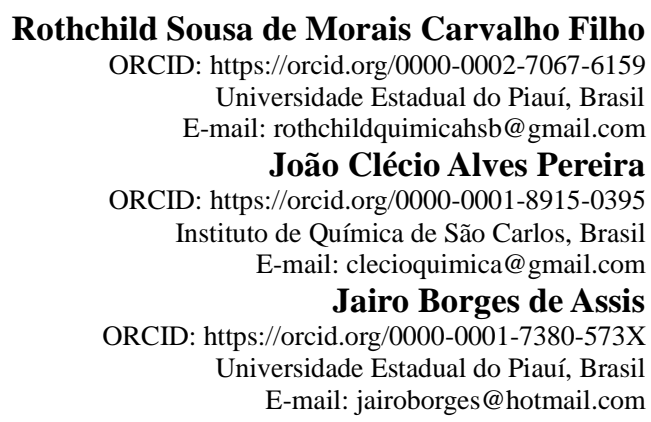

\begin{abstract}
Resumo
Os indicadores naturais ácido-base são corantes extraídos de partes de plantas. Esses corantes apresentam cromóforos em sua composição, substância responsável pela variação de coloração em função do pH. O chapéu-de-napoleão (Thevetia peruviana (pers.) K. Schum) é uma planta arbustiva, de textura lenhosa e lactescente. o objetivo desse estudo foi avaliar o potencial do chapéu-de-napoleão (Thevetia peruviana (pers.) K. Schum) como novo indicador natural ácido-base e estudar o compartamento da estabilidade térmica desse corante natural. $\mathrm{O}$ extrato aquoso do chapéu-de-napoleão apresentou excelente variação de coloração em função do pH em meio básico e em caráter ácido, não apresentou variação de coloração, ficando incolor, desse modo, apresentou característica semelhante do indicador renomado fenolftaleína. Além disso, o extrato natural apresentou excelente estabilidade térmica, não oxidando no período em estudo, vindo a ser um excelente indicador natural ácido-base de fácil aquisição e baixo custo para ser usado no ensino de Química.
\end{abstract}

Palavras-chave: Estabilidade térmica; Thevetia peruviana; Indicador ácido-base.

\begin{abstract}
Acid-base natural indicators are dyes extracted from plant parts. These dyes have chromophores in their composition, a substance responsible for color variation as a function of $\mathrm{pH}$. The Napoleon's Hat (Thevetia peruviana (pers.) K. Schum) is a shrubby plant with a woody and lactescent texture. the aim of this study was to evaluate the potential of napoleon's hat (Thevetia peruviana (pers.) K. Schum) as a new natural acid-base indicator and to study the thermal stability behavior of this natural dye. The aqueous extract of napoleon's hat showed excellent color variation as a function of $\mathrm{pH}$ in basic medium and in acidic character, it did not show color variation, becoming colorless, thus, it presented similar characteristics to the renowned phenolphthalein indicator. In addition, the natural extract presented excellent thermal stability, not oxidizing during the period under study, becoming an excellent natural acid-base indicator that is easy to acquire and has a low cost to be used in the teaching of Chemistry.
\end{abstract}

Keywords: Thermal stability; Thevetia peruviana; Acid-base indicator.

\section{Resumen}

Los indicadores ácido-base naturales son tintes extraídos de partes de plantas. Estos tintes tienen cromóforos en su composición, sustancia responsable de la variación de color en función del pH. El sombrero de Napoleón (Thevetia peruviana (pers.) K. Schum) es una planta arbustiva de textura leñosa y lactescente. El objetivo de este estudio fue evaluar el potencial del sombrero de napoleón (Thevetia peruviana (pers.) K. Schum) como un nuevo indicador ácidobase natural y estudiar el comportamiento de estabilidad térmica de este tinte natural. El extracto acuoso de sombrero de napoleón mostró una excelente variación de color en función del pH en medio básico y en carácter ácido, no mostró variación de color, por lo que se volvió incoloro, por lo que presentó características similares al reconocido indicador de fenolftaleína. Además, el extracto natural presentó excelente estabilidad térmica, no oxidando durante el período en estudio, convirtiéndose en un excelente indicador ácido-base natural, fácil de adquirir y de bajo costo para ser utilizado en la enseñanza de la Química.

Palabras clave: Estabilidad térmica; Thevetia peruviana; Indicador ácido-base. 


\section{Introdução}

Extratos oriundos de partes das plantas (raízes, troncos, folhas, flores, frutos, galhos etc) são ricos em cromóforos capazes de mudar de coloração em função do pH, apresentando característica de indicador ácido-base (Skoog et al., 2015; Uchôa et al., 2016; Penaforte \& Santos, 2014; Silva et al., 2020).

Os pigmentos naturais vêm sendo utilizados com frequência como indicadores ácido-base, como alternativa aos indicadores sintéticos, como fenolftaleína, azul de bromotimol, vermelho de metila, entre outros (Couto, Ramos \& Cavaleiro, 1998; Silva et al., 2020).

Os indicadores naturais são soluções fracas; isto é, apresentam um valor de pH próximo ao pH neutro, adicionados a uma determinada solução, eles ligam-se a íons $\mathrm{H}^{+}$ou $\mathrm{OH}^{-}$e mudam de cor devido a uma alteração na configuração eletrônica (Uchôa et al., 2016; Carvalho Filho \& Pereira, 2021; Silva et al., 2020).

A ligação que ocorre com estes íons provoca uma mudança na configuração eletrônica destes extratos, tal alteração deve ser um dos principais motivos responsáveis pela variação de coloração presente no meio (Carvalho Filho \& Pereira, 2021; Uchôa et al., 2016). O valor de pH é o fator de maior influência na variação de coloração apresentado pelas antocianinas, visto que, em função de sua acidez ou basicidade, estas podem apresentar diferentes estruturas (Lee, Durst \& Wrolstad, 2005).

Durante o século XVIII, notou-se que nem todos os indicadores apresentavam as mesmas mudanças de cor. Em 1775, Bergman escreveu que extratos de plantas azuis são mais sensíveis aos ácidos, ou seja, possuem uma variação gradual de cor, que pode diferenciar ácidos fortes de fracos (Berg, 1958; Harbone \& Grayer, 1988).

A temperatura de extração dos corantes deve ser cuidadosamente controlada, pois se sabe que esses pigmentos são termicamente estáveis até $60^{\circ} \mathrm{C}$ (Terci \& Rossi, 2004; Di Carlo et al., 1999; Dias et al., 2003). Por serem sensíveis ao aquecimento, altas temperaturas podem afetar as concentrações de antocianinas nos extratos por favorecer a extração conjunta de ácidos fenólicos e taninos, além de complexações dos pigmentos com proteínas, o que compromete a estabilidade dos extratos.

A temperatura de armazenamento também é um fator que influencia na degradação e no aparecimento de fungos nos extratos. Estudos indicam que extratos armazenados a baixas temperaturas são mais estáveis quando comparados àqueles armazenados à temperatura ambiente (Janna, 2007; Favaro, 2007).

Extratos são mais estáveis sob proteção da luz quando comparados àqueles que permaneceram expostos à luz. A radiação UV interage no extrato de maneira a facilitar reações como, por exemplo, copigmentação com outros compostos presentes alterando a estabilidade das antocianinas, além de favorecer a formação de produtos de degradação oxidativa das antocianinas que possuem coloração marrom (Bailoni, Bobbio \& Bobbio, 1999).

Logo, o objetivo desse estudo foi avaliar o potencial do estrato aquoso das flores do chapéu-de-napoleão (Thevetia peruviana (pers.) K. Schum) como novo indicador natural ácido-base e estudar o comportamento da estabilidade térmica desse corante natural.

\section{Metodologia}

\section{Obtenção da matéria prima}

As flores do chapéu-de-napoleão foram colhidas em Piracuruca, Piauí, Brasil. Em seguida, foram ledas para o laboratório de Química da Universidade Estadual do Piauí - UESPI, campus Piripiri - PI. 


\section{Preparo do Indicador e das Soluçães}

Para obtenção das antocianinas, na forma de extrato natural, utilizou-se água destilada e $10 \mathrm{~g}$ de amostra do indicador (chapéu-de-napoleão). O extrato foi preparado, com adição de $10 \mathrm{~g}$ de amostra em $50 \mathrm{~mL}$ de água e aquecido até a fervura. Em seguida, a solução foi resfriada e filtrada.

As soluções que foram utilizadas para este experimento estão organizadas em ordem crescente de acidez e basicidade (de fraco a forte). Durante os testes dos extratos, utilizou-se nessa sequência: Suco de Limão, Vinagre, Sabão em Pó e Hidróxido de Sódio.

As soluções sólidas foram pesadas 2,5 $\mathrm{g}$ e as líquidas medidas 2,5 $\mathrm{mL}$ de cada. Logo após, todas foram diluídas e transferidas para um balão volumétrico de $50 \mathrm{~mL}$ até atingir o menisco, chegando a uma concentração de 5\% (Uchôa et al., 2016).

\section{Teste da Estabilidade Térmica}

Testou-se a estabilidade térmica do extrato aquoso do chapéu-de-napoleão (Thevetia peruviana (pers.) K. Schum), acondicionando 2 amostras do extrato em temperaturas diferentes: $0{ }^{\circ} \mathrm{C}$ (acondicionadas no congelador) e $25^{\circ} \mathrm{C}$ (temperatura ambiente). A amostra à $25^{\circ} \mathrm{C}$ foi analisada em período de 10 e 20 dias e a amostras à $0{ }^{\circ} \mathrm{C}$ foi analisada com 30 dias no intuito de estudarmos a estabilidade dessas amostras em condições diferentes (Carvalho Filho \& Pereira, 2021).

\section{Resultados e Discussão}

\section{Descrição das Plantas}

O chapéu-de-napoleão (Figura 1) com nome cientifico Thevetia peruviana (pers.) K. Schum é popularmente conhecido devido à forma de seus frutos, também chamado com Acaimirim, Auaí-guaçu, Cerbera, Noz-de-cobra, é uma pequena árvore originária da América Central, mas largamente distribuída em todas as regiões tropicais devido ao seu aspecto ornamental (Schvartsman, 1979) e pertencente à família Apocynaceae.

Figura 1: Chapéu-de-napoleão (Thevetia peruviana (pers.) K. Schum).

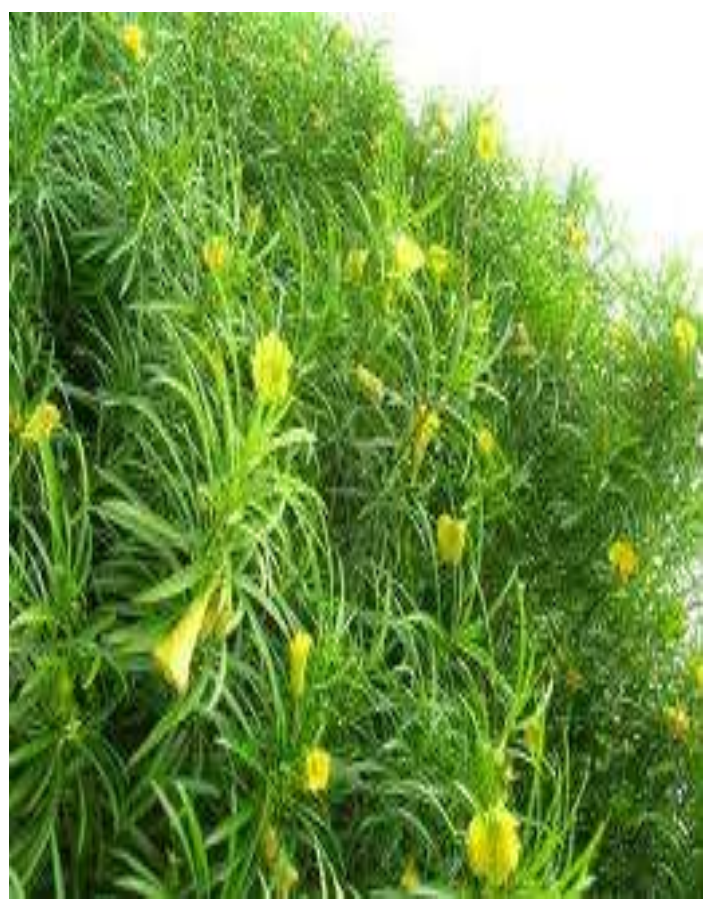

Fonte: Autores. 
Esta planta é arbustiva, de textura lenhosa e lactescente (seiva leitosa) com caule único e porte de 3 a 4 metros. As flores são muito bonitas, tubulares, perfumadas, de coloração laranja ou amarela. Ocorrem ainda variedades de flores brancas ou róseas. Os frutos dessa árvore são responsáveis por casos graves de intoxicações, em especial em crianças, que comem suas castanhas. Os principais componentes tóxicos pertencem à classe dos glicosídeos cardiotóxicos (Oliveira \& Godoy, 2003).

\section{Uso como indicador}

O extrato aquoso obtido das flores da Thevetia peruviana, apresentou coloração amarela. O extrato aquoso em contanto com as soluções, exibiu colorações extremas em meio básico, variando desde o verde até o amarelo, já em meio ácido, o indicador não apresentou variação de coloração, tornando o meio ácido incolor, mostrando semelhança com o indicador renomado fenolftaleína, o que pode ser acompanhado na Figura 2.

Figura 2: Variação de coloração em função do pH.

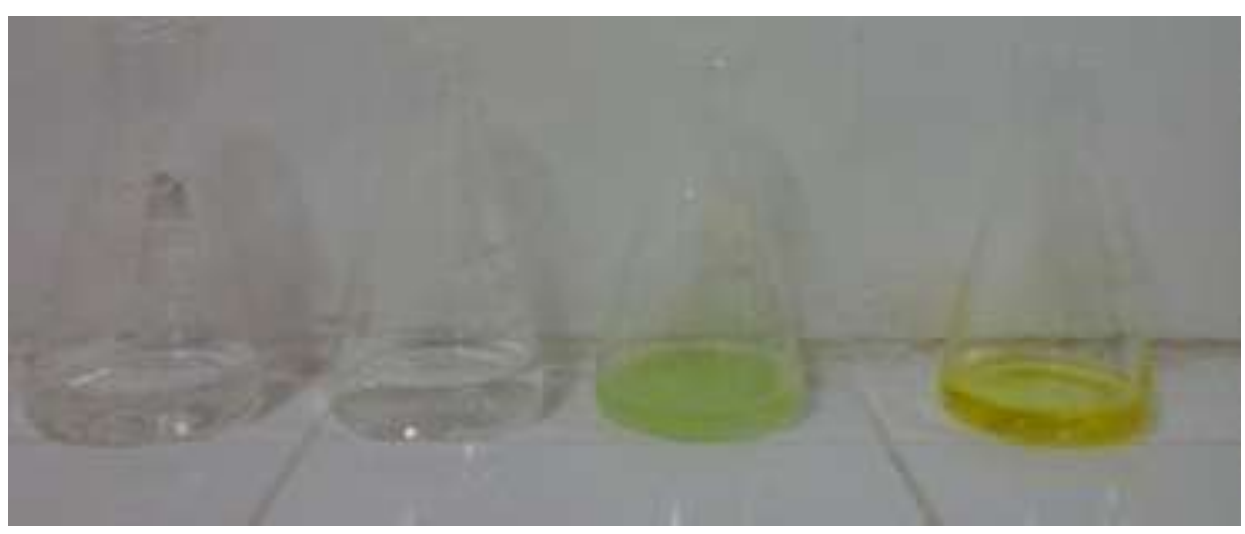

Fonte: Autores.

Verificou-se (Figura 2) que as tonalidades finais das soluções a 5\% mais o extrato aquoso apresentaram características semelhantes; pois ambas as soluções ácidas apresentaram colorações incolor e as bases apresentaram colorações bem próximas do verde.

A variação de coloração apresentada na Figura 3, em cada meio, pode ser melhor visualizado na Tabela 1.

Tabela 1 - Cores apresentadas pelas soluções em contado com o extrato aquoso em função do pH.

\begin{tabular}{|c|c|c|c|c|}
\hline \multicolumn{2}{|c|}{ Soluções a 5\% em solução } & pH & $\begin{array}{l}\text { Coloração inicial das } \\
\text { solucões a } 5 \%\end{array}$ & Coloração final das soluções a $5 \%$ mais \\
\hline A & Suco de Limão & 2 & Incolor & Incolor \\
\hline B & Vinagre & 4 & Incolor & Incolor \\
\hline $\mathrm{C}$ & Sabão em Pó & 10 & Incolor & Verde Claro \\
\hline $\mathrm{D}$ & Hidróxido de Sódio & 14 & Incolor & Verde Amarelado \\
\hline
\end{tabular}

Fonte: Autores. 
Observa-se na Tabela 1 que o extrato das flores do chapéu-de-napoleão, demonstrou-se como excelente indicador natural ácido-base devido à sua capacidade de variação de coloração em função do pH das soluções estudadas, comprovando a eficácia desse indicador em soluções laboratoriais e também em soluções comerciais.

Os resultados obtidos indicam que extrato aquoso obtido das flores do chapéu-de-napoleão utilizado neste trabalho pode ser usado para medidas de $\mathrm{pH}$ em meio aquoso, devido sua excelente variação estrutural (tonalidade) em função do $\mathrm{pH}$, podendo ser um excelente indicador natural para o estudo de ácido-base, podendo ser um substituto para a fenolftaleína devido ao seu excelente potencial me meio básico, apresentando mais de uma variação de coloração. Dessa forma, os achados desse trabalho tornam-se um guia para novos trabalhos com o uso das antocianinas desse corante em diversos experimentos da área de química, como também, no desenvolvimento de trabalhos voltados para área alimentícia, uma vez que esses pigmentos (antocianinas) são fundamentais para a indústria de alimentos.

\section{Estabilidade térmica}

A Tabela 2 apresenta a estabilidade térmica do extrato do chapéu-de-napoleão em temperatura de $0{ }^{\circ} \mathrm{C}$ em período de 30 dias e $25^{\circ} \mathrm{C}$ em período de 10 e 20 dias.

Tabela 2. Estabilidade Térmica do Indicador.

\begin{tabular}{ccc}
\hline Período & \multicolumn{2}{c}{ Temperatura } \\
& $0{ }^{\circ} \mathrm{C}$ & $25^{\circ} \mathrm{C}$ \\
10 dias & - & Não Oxidou \\
20 dias & - & Não Oxidou \\
30 dias & Não Oxidou & - \\
\hline
\end{tabular}

O extrato aquoso da chapéu-de-napoleão apresentou uma excelente estabilidade térmica ao longo do período em estudo, demonstrando mais uma vez o seu potencial como indicador natural, não apresentando perda de coloração, fato apresentado por muitos corantes naturais, o que compromete a aplicação do extrato como indicador (Coelho, 2011; Uchôa et al., 2016).

\section{Conclusão}

De acordo com os resultados obtidos, pode-se concluir que o extrato aquoso das flores do chapéu-de-napoleão apresentou excelente estabilidade térmica e significativa variação de coloração em função do $\mathrm{pH}$ em temperaturas e períodos distintos, podendo ser utilizado como novo indicador natural ácido-base, de fácil acesso, baixo custo, eficiente com materiais do cotidiano. Isto pode servir para melhorar o ensino de Química, vindo a ser um concorrente de peso aos indicadores naturais e sintéticos presente na literatura.

\section{Referências}

Bailoni, M. A., Bobbio, P. A. \& Bobbio, F. O. (1999). Stability of the anthocyanins from Acalipha hispida and copigmentation effect. Acta Alimentaria. 28(2), 161-169.

Benite, A. M. C. \& Benite, C. R. M. (2009). O laboratório didático no ensino de química: uma experiência no ensino público brasileiro. Ibero americana de Educación. 48(2), 1-2.

Carvalho Filho, R. S. C. \& Pereira, J. C. A. (2021). Novo indicador natural ácido-base para o ensino de química a partir da euphorbia leucocephala lotsy. ln: PEREIRA, J. C. O Ensino e a Pesquisa em Química. https://doi.org/10.22533/at.ed.280212608. 
Research, Society and Development, v. 10, n. 12, e101101220263, 2021

(CC BY 4.0) | ISSN 2525-3409 | DOI: http://dx.doi.org/10.33448/rsd-v10i12.20263

Coelho, A. G. (2011). Estudo da degradação térmica de antocianinas de extratos de uva (Vitis vinifera L. 'Brasil') e jabuticaba (Myrciaria cauliflora). 98p. Dissertação (Mestrado em Química Analítica) - Departamento de Química. Universidade Estadual de Campinas.

Couto, A. B., Ramos, L. A. \& Cavalheiro, E. T. G. (1998). Aplicação de pigmentos de flores no ensino de química. Química Nova, 21 (2), $221-227$.

Curtright, R., Rynearson, J. A. \& Markwell, J. (1996). Anthocyanins Model compounds for learning about more than pH. J. Chem Educ, 73 (4), $306-309$.

Di Carlo, G., Mascolo, N., Izzo, A. A. \& Capasso, F. (1999). Review article: Flavonoids old and new aspects of a class of natural therapeutic drugs. Life Sci, 65 (4), 337-353.

Dias, M. V. D., Guimarães, P. I. C. \& Merçon, F. (2003). Corantes Naturais: Extração e emprego como Indicadores de pH. Quimica Nova, $17,27-31$.

Dreosti, I. E. (2000). Antioxidant polyphenols in tea, cocoa, and wine. Nutrition, 692, 7-8.

Harborne, J. B. \& Grayer, R. J. (1998). The anthocyanins. In: GRAYER, R. J. The flavonoids: advances in research since 1980. Chapmam \& Hall, London, 120 .

Favaro, M. M. A. (2007). Extração, estabilidade e quantificação de antocianinas de frutas típicas brasileiras para aplicação industrial como corantes. 102p. Dissertação (Mestrado em Química) - Instituto de Química. Universidade Estadual de Campinas, Campinas.

Janna, O. A., Khairul, A. K. \& Maziah, M. (2007). Anthocyanin stability studies in Tibouchina semidecandra L. Food Chemistry, 101 (4), $1640-1646$.

Lee, J., Durst, R. W. \& Wrolstad, R. E. (2005). Determination of total monomeric anthocyanin pigment content of fruit juices, beverages, natural colorants, and wines by the $\mathrm{pH}$ differential method: Collaborative study. Journal AOAC International, 88 (5), 1269-1278.

Oliveira, R. B. \& Godoy, S. A. P. (2003). Plantas tóxicas: conhecimento para a prevenção de acidentes. Holos, 1, 64 p.

Penaforte, G. S. \& Santos, V. S. (2014). O ensino de química por meio de atividades experimentais: aplicação de um novo indicador natural de pH como alternativa no processo de construção do conhecimento no ensino de ácidos e bases. Educamazônia, 8(2), 8-21.

Schavartsman, S. (1979). Plantas venenosas. Sarvie, 176 p.

Skoog, D. A., West, D. M., Holler, F. J. \& Crouch, S. R. (2015). Fundamentos de Química Analítica. (9a ed.). Cengage Learning.

Silva, W. A., Moura, F. J. A., Sousa, J. L. S. \& Correia, J. M. (2020). A utilização do indicador natural para a aplicação de uma atividade experimental no ensino de química. Brazilian Journal of development, 6(4), 16859-16871.

Terci, D. B. L. \& Rossi, A. V. (2002). Indicadores naturais de pH: usar papel ou solução? Quimica Nova, 25(4), 684-688.

Uchôa, V. T., Carvalho Filho, R. S. M., Lima, A. M. M., \& Assis, J. B. (2016). Utilização de plantas ornamentais como novos indicadores naturais ácido-base no ensino de química. Holos, 32(2), 152-165. 